2006-2428: ENGINEERING "DISCOVERY"-AN ENTRANCE TO THE PROFESSION

Donald Bunk, Rensselaer Polytechnic Institute

Douglas Baxter, Rensselaer Polytechnic Institute

Henry Sneck, Rensselaer Polytechnic Institute 


\title{
Engineering "Discovery" - An Entrance to the Profession
}

\author{
Douglas H. Baxter \\ Donald S. Bunk \\ Henry Sneck \\ Rensselaer Polytechnic Institute \\ School of Engineering
}

\begin{abstract}
Many students entering into the study of Engineering have not chosen departmental majors. Perhaps more importantly they may not know what Engineers do as they ply their profession, and may have a misleading or unrealistic perception of their career choice.

Engineering "Discovery" is a course intended for students entering an engineering curriculum. By using carefully chosen artifacts such as electric toasters and warm-mist room humidifiers students learn how engineers apply physics principles, most already learned in secondary school, in the design of such products. They observe the artifacts and sub-systems and their interconnectivity and speculate on the thought and problem solving processes used by practicing engineers in developing the product. A unique requirement is that students report their findings using both solid modeling, technical reports and memorandums, problem solving, and presentation.
\end{abstract}

\section{Introduction}

It is safe to say that few entering Engineering students have an idea of what practicing Engineers really do. They arrive at college with a variety of expectations which are often not realized until they reach their Junior or Senior years. Their backgrounds in mathematics and science are probably strong, and they may have participated in science fairs or class projects that are related to technology. However, they most likely have little or no sense of the complexity and attention to detail that Engineering requires, or just how Engineers work and think as they solve engineering and design problems.

Some engineering schools have required first semester courses which are intended to acquaint students with the different disciplines offered at the school. These "Introduction to Engineering" courses are usually in the form of a series of presentations by department faculty from the various disciplines. They may have literature available, use laboratory demonstrations, and discuss the variety of positions open to their discipline in industry. They may also mention opportunities for graduate study in their field and the availability of research and doctoral study.

The remainder of the student's schedule in their first year usually consists of courses dealing with a fundamental body of knowledge as presented in the required mathematics, physics, computing, and other science courses, and possibly an "Engineering Science" course. Often 
there is little exposure to engineering professors and the practice of engineering in the lower division course sequence.

As students progress into the upper division courses within their department or program they may take project-driven courses or courses with projects imbedded in them that are specific to the subject. Often the relationship between science, engineering, science, mathematics, and engineering is not integrated, but remains veiled. Students proceed through fours years of study in engineering learning fundamentals but little about the profession they are about to enter. Students who have a meaningful cooperative engineering experience with an industrial sponsor do gain some insight into the-day-to-day work of the engineer.

What is described here is an attempt to introduce students to the engineering profession by using a "Discovery" experience in the first semester as a transitioning course from their previous mathematics and science experience in high school. It provides the student with some insight to the use of physics principles by engineers in the design of products, the identification of the subsystems and their inter-relation, and the attention to detail required by the profession. It illustrates the interdisciplinary nature of modern engineering and allows students to "Discover" not only the physics principles which drive design, but what the engineering profession is really about. The "Discovery" concept affords the student the opportunity to actually practice the profession rather than reading about it or listening to lectures that describe various disciplines.

\section{The Discovery Concept}

Many engineering schools have introduced engineering "design" in their first semester or first year curriculum. For the most part they really are not design courses simply because the students have not received the background necessary to do bonifide design work. We believe that it is too early to expect students to do meaningful "design". They may not be fully prepared to do so, even as seniors. Approaches such as building working systems from kits, doing "paper" designs, or making balsa or foamcor models to solve "design" problems do not accurately portray the engineering process. A more realistic approach is to engage the student in playing the role of an engineer to "Discovery" how engineers use mathematics, science principles, and engineering fundamentals in the practice of engineering.

Introducing students to the profession through the concept of "Discovery" we believe is unique and has the potential for reshaping first year Engineering curricula. Discovery is not "reverse" engineering or "re-engineering", but rather uses existing commercial products so that students "discover" the underlying physics principles and used by engineers in creating the product. The "Discovery" concept is also intended to pique and develop the student's curiosity, a trait common to successful engineering practitioners. The vehicle used in the "Discovery" concept may be a common household product that is not costly, can be used on a table-top and stored easily, is easily disassembled and assembled, is safe, has a small number of components and at least three identifiable sub-systems, and involves at least three engineering disciplines.

First, the students are asked to "discover" the underlying physics principles upon which the device, system, or product operates. Some will be apparent from their previous knowledge of high school physics and mathematics. Some will come from their current studies; and some will 
come from their own research as they learn to take responsibility for their learning. It is intended that the student's will find themselves in an environment where they will begin the process of learning to learn!

Secondly, students "discover" how Engineers rely on and use a "fundamental body of knowledge" in the product or system design process. In other words, they will begin to see how engineers expand on the physics principles with their own empirical equations and constants to perform the design calculations necessary to size parts and verify concepts.

The students discover the basic physics principles that drive the design and functioning of common household products and artifacts. They "discover" the products sub-systems and the interconnectivity that allows it to function as desired. They also learn to develop function block diagrams as a method of illustrating this interconnectivity. They learn how to create simple experiments and use a "hands-on" investigation process to gain an understanding of the artifact and to make predictions regarding its behavior. Finally, they learn the necessity of paying attention to detail and that the engineers work is very detailed, even in what may appear to be an uncomplicated artifact.

The students also begin to identify the choices the engineer needs to make in creating the product as design details emerged from the conceptual stage of the process. They begin to realize how engineers work on problems and make decisions as they become aware of the open-endedness inherent in the design process itself.

Student and faculty feedback from open-ended, project-driven design experiences at the first year level indicate that they are time consuming for student and faculty, and are prone to failures as unforeseen design problems arise. Students should have a success experience and gain confidence that engineering was a good career choice them. To assure this in Discovery requires significant faculty guidance in the early stages of the "Discovery" process to assure understanding of design decisions, identify sub-systems, and uncover physics and engineering principles. As the student develops confidence and background they are encourage to take more and more of the "Discovery" experience on their shoulders and will have gain an experience that will be valuable as they continue their engineering education.

\section{Choosing the Artifact}

As mentioned earlier our concept of "Discovery" is to have entering students discover engineering by practicing it instead of just talking about it as is the case with more traditional introductory courses. We have ruled out "design oriented courses" based on our observation that it is unrealistic to expect freshman students to do any meaningful design. Students just out of high school are ill-prepared for "design," and they may still be as capstone-design seniors.

By 'discovery' we do not mean reverse engineering where the students discover how things are, but probably not why. We suggest it is better to engage engineering students in role-playing as engineers so they discover how engineers use mathematics, science, engineering fundamentals, and communications in the practice of engineering. To accomplish this discovery we use common, everyday artifacts that satisfy the following requirements. 
- Small enough to fit on a table-top

- Easy to assemble and disassemble

- Safe to use in the classroom

- Consists of at least three sub-systems and a small numbers of components

- Involves at least three engineering disciplines in some depth

- Permits some team work, but mostly individual work, in and out of class

- Uses physical principles that are taught in high school physics or undergraduate physics texts

- Require only high school mathematics and avoids calculus

We have found an inexpensive $\$ 20$ electric toaster (Figure 1) to be a device that allows the student to "Discover" much about the engineering process. One toaster for every four students allows access to this artifact by all the students. A tool kit is also provided for each group of four students that contains the instruments, hand tools, measuring devices, etc., that are necessary to "discover" the artifact. All of the hands-on activities with the toaster and the tool-kit are preformed in class in a four person group setting.

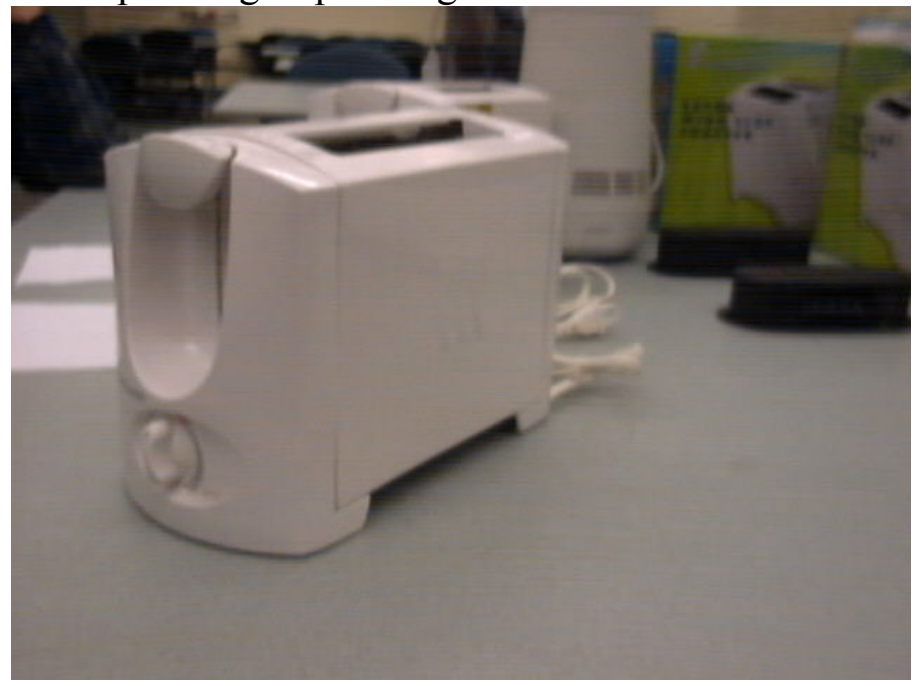

Figure 1: 2 Slice Electric Toaster

The electric toaster allows first term engineering students to "Discover" many design considerations and several physics principles such as:

- Conduction, convection, radiation heat transfer

- Ohm's Law

- Electrical energy dissipation

- Electrical resistance/resistively property

- Electromagnetism

- Energy and power balances

- Kinetic, potential and elastic energy storage

- Electrical timing circuits

- Materials properties and selection

- Manufacturing processes, assembly, fasteners 
- Integrated electrical circuits

- Electrical potentiometers and switches

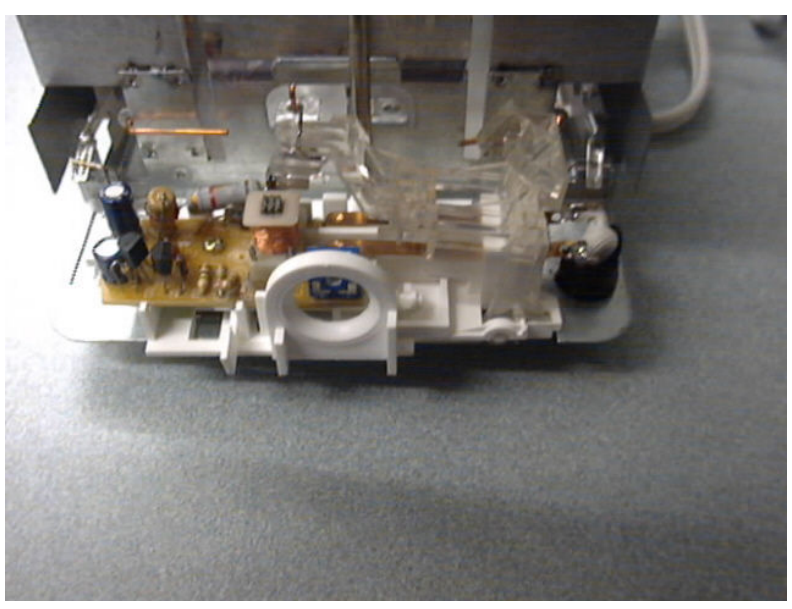

Figure 2: Timing Sub-System for the Toaster

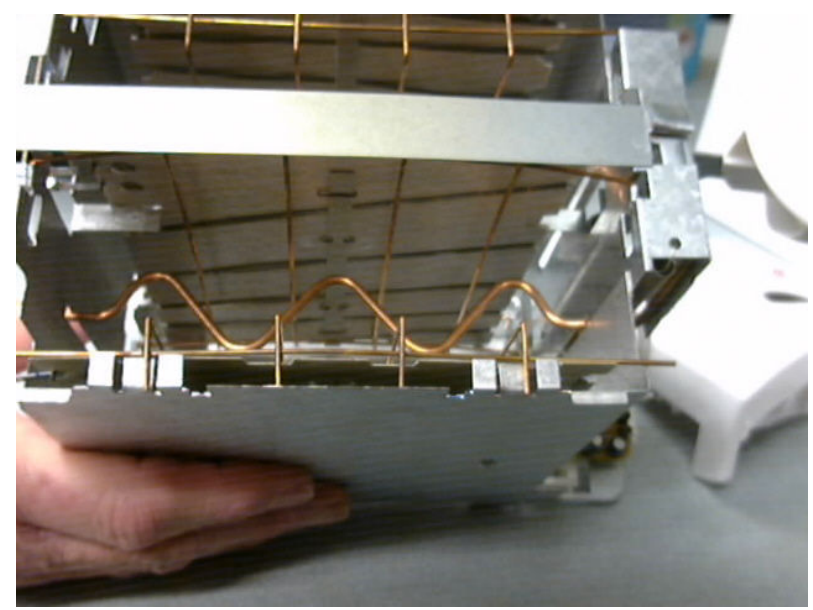

Figure 3: Toaster Heating Coils and Internal Lift Sub-Systems

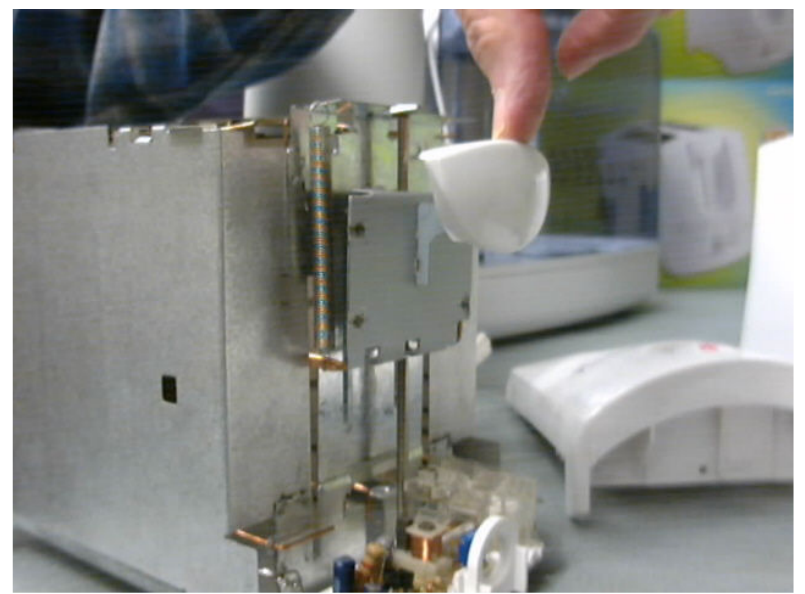

Figure 4: Toaster Lift Sub-System 
During their discovery of these engineering topics students learn of the inter-connectivity of the electric toaster components and sub-systems (Figures 2-4). This leads them naturally into functional decomposition and engineering function block diagrams. The discovery of how "the toaster" was "engineered" requires about twenty classroom hours, and about as many outside hours in homework assignments. That leaves time for a second artifact-discovery, this time with less faculty leadership and more individual student discovery. During these remaining sessions the students discover the engineering of a second artifact. For this we chose a warm-mist room humidifier. The physics and engineering topics discovered here are:

- Hydrostatics

- Ideal gas law

- Thermal capacitance

- Power balances

- Conservation of energy

- Boiling heat transfer

- Vaporization rate

- Conservation of mass

- Latent heat of vaporization

- Electrical energy dissipation

- Thermostatic control

- Fluid level regulation

With a few exceptions the students are familiar with the physical principles involved, but initially not how they can be applied to the operation of the humidifier. In their final report they explain how it works in engineering terms.

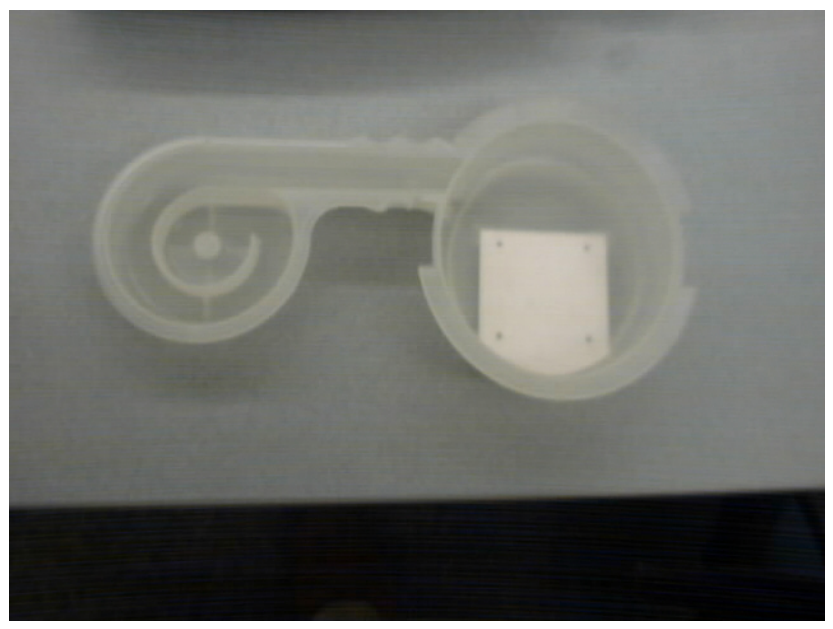

Figure 5: Humidifier Water Delivery and Heater Sub-Systems 


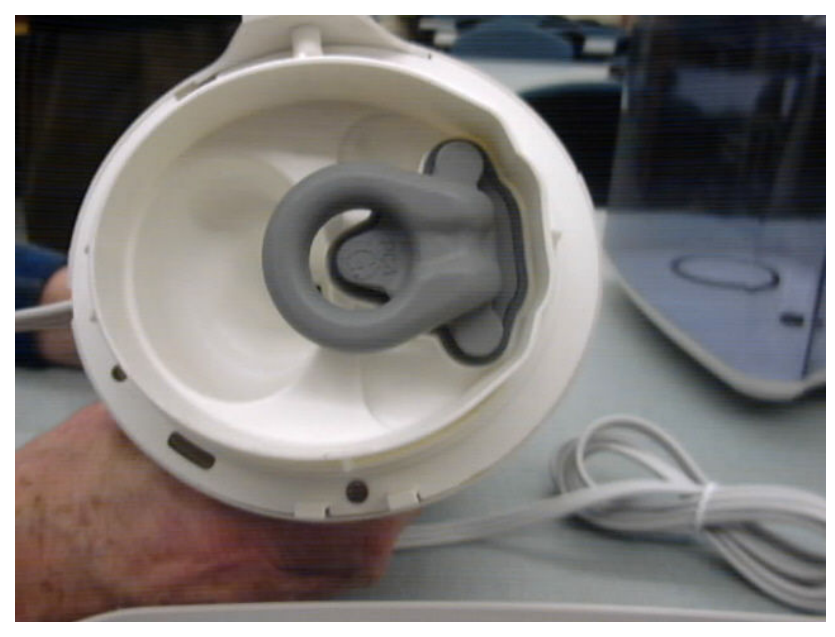

Figure 6: Heating Coil Sub-System

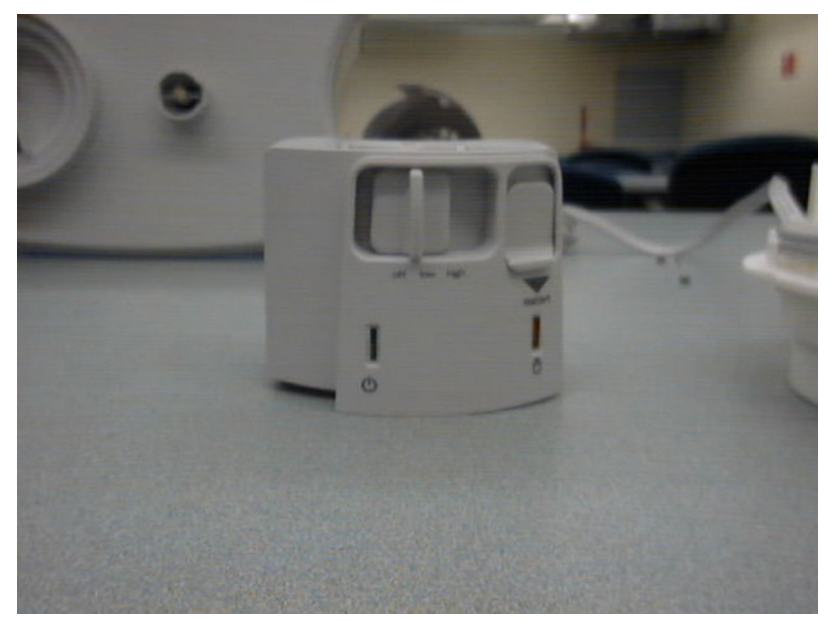

Figure 7: Humidifier Control Sub-System

\section{Course Delivery}

The "Discovery" process as described above is artifact-driven. Some of the topics listed above are reviewed interactively in class when appropriate. Out-of-class student work often requires writing memos describing their research findings, e.g., the difference between the three modes of heat transfer. The calculations performed as homework are submitted using a format for engineering calculations.

Professionalism and engineering practice are emphasized throughout the "Discovery" process, in class and outside of class. The homework's are graded based on content and professional presentation quality. Feedback is used as a teaching tool through instructor written comments and reviews with the students. Students are encouraged throughout the course to take responsibility for their learning with faculty guidance and encouragement. 
Most of the physics principles encountered are found in their physics course text, and those that are not, e.g., boiling heat transfer, are introduced in class. Learning is re-enforced via memo writing exercises in which the students report the results of their research into assigned topics. Each artifact requires a team-written final report that addresses assigned topics. Classroom time ( $2 \mathrm{hrs} /$ week) is spent interactively discussing the engineering process and the physics/engineering principles used by engineers. Simple field-measurements are performed in class to obtain data (e.g., resistance, spring constants), and to compare with that results of mathematical modeling and calculations.

For the most part student's submissions are individual efforts. The exceptions are field measurements and the preparation of the artifact final reports that are prepared by four person teams. The project final report is developed in three stages: outline, draft, and final version. The first two stages are not graded but critiqued by faculty before the final version is written by the team. These reports must conform to the standard engineering format. Each member must identify their contribution to the final report. All members are required to make a technical contribution to the report, as well as to contribute to the written text. Guest faculty occasionally present relevant topics in class such as manufacturing, electrical, timing circuits, material selection etc. These presentations serve to broaden the student appreciation of the profession as a whole. Late attendance is not tolerated and unexcused homework submissions, receive little credit. Homework submissions are required to be neatly written, properly referenced, and generally of professional quality.

\section{Engineering Graphics with Engineering Discovery}

Early in the planning stages of the Engineering Discovery course, it was recognized that engineering graphics could be an essential element in the course. As students examined parts and sub-assemblies of the toaster, they could also be creating solid models of the toaster parts and assemblies.

Presently, students are required to take a one credit course in engineering graphics during their freshman year. Students who took Engineering Discovery took a special section of engineering graphics where the emphasis was two-fold. First, students modeled the toaster and created the models along with their work in Engineering Discovery. The models were created in SolidWorks. SolidWorks is installed on the student laptops so the students can work on their own laptop. Second, engineering graphics was presented in a larger scope of Technical Communications. In addition to working on the engineering graphics, students were also taught how to write engineering memos and technical reports. Emphasis was placed on showing students how to imbed graphical information in a report and how to properly reference the figures in the report.

An example of the toaster work is shown in Figures 8-10 below. It should be noted that students were not required to build the entire toaster. Several of the parts were given to the students or were partially built and then given to the students. The goal was to have the students working on two parts or assemblies (with associated drawings) each week. Note that the entire toaster is not modeled (for example, the electronics are greatly simplified). Some simplifications in geometry 
were made to allow for the students modeling skills. However, despite these adjustments, the final solid model was very satisfactory.

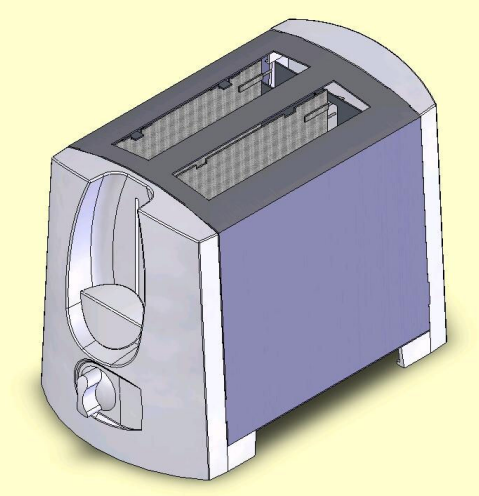

Figure 8: Toaster as built in SolidWorks

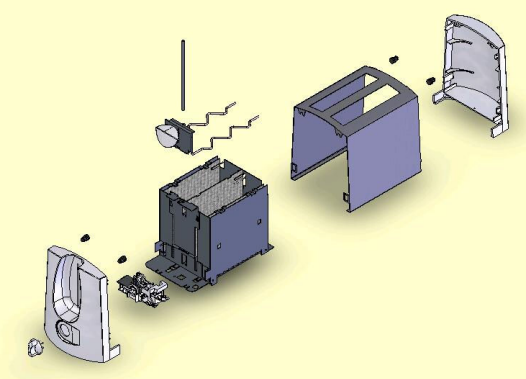

Figure 9: Exploded view of the toaster in SolidWorks

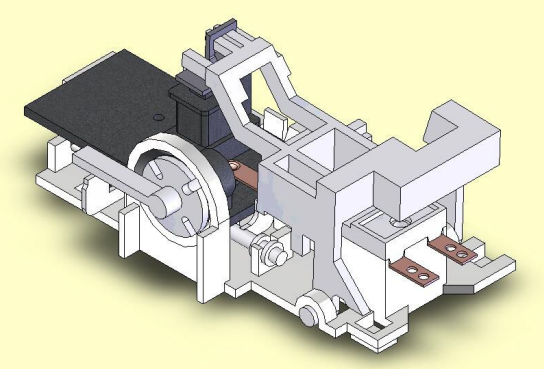

Figure 10: Control Assembly as modeled in SolidWorks

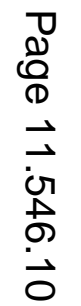




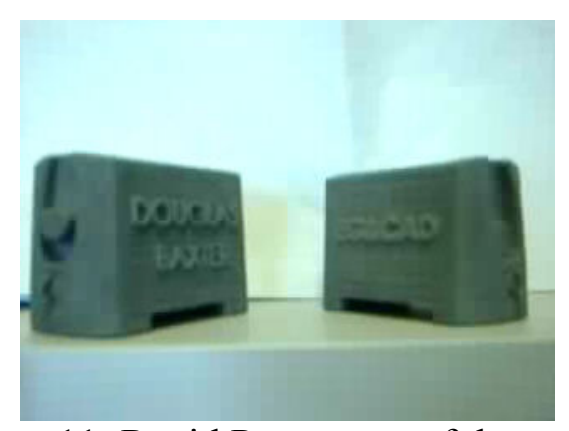

Figure 11: Rapid Prototypes of the toaster

In Figure 11, two starch models of the toaster were shown. A brief module in rapid prototyping was included in the students' course work. Students simplified their toaster assembly in SolidWorks and submitted a $1 / 4$ scale model to the Z-Corporation 3D printer. Students could emboss their name on the side of the toaster and make a small desk top decoration for themselves. This small introduction into rapid prototyping proved to be very popular with the students.

\section{Observations}

"Discovery" has been taught twice with modest modifications, using the same two artifacts. The students find the course goals and structure are very different from their high school experience. Some are uncomfortable with the written assignments, asking to be told more about what is expected. This response is not unexpected because one of the course goals is to encourage the freshman to take more responsibility for their own education and rely less upon the instructor.

We found that first term students are more receptive to the course goals and format than second term students who appeared to be operating more in a "survival mode" after their first term.

Some students' reading and comprehension skills appear lacking. Students claim there is too much writing, too many memos, and fussy calculations. This seems to be a common complaint heard in other courses which require written submissions.

Each new artifact requires the re-invention of the planned day-by-day class scenarios. The preparation of artifact-driven course requires considerable faculty time and special faculty classroom skills. Not all faculty can, or are willing to, participate in a course that requires this amount of preparation and engineering experience. The reading and grading of the collected assignments cannot be left to inexperienced teaching assistants who have little if any design or engineering experience.

Our experience indicates that this course is best suited to sections of about thirty students with two instructors, or one instructor and an experienced graduate TA. This size permits a manageable hands-on experience for each student, a feature of this course the students enjoy. 


\section{Conclusions}

The evaluation of the effectiveness of a course like this is difficult for several reasons. First, the students have no bench-mark to use for their judgment of the course because its goals and its delivery are unlike any course they may have taken or, for that matter, will take. As with many courses the long-term benefits cannot obviously be assessed in the short term. The students who took this course will be tracked throughout their educational career to collect their impressions of "Discovery" as they reflect back upon it in the context of their subsequent education. Determining whether we have succeeded in our goal of helping students discover the profession of engineering will depend on the long-term tracking feedback.

\section{Bibliography}

1. Wohleber, Curt, “The Toaster”, Invention and Technology, Fall 2005.

2. Baxter, Douglas H., and Mandigo, Andrew, "Comparing Different Teaching Models in a First Year Computer Aided Design Course," Proceedings, American Society of Engineering Education: Annual Meeting, Portland, Oregon, June 2005.

3. Baxter, Douglas, H., "Integrating Computer Aided Design with Technical Communications in a Freshman Engineering Program," Proceedings, American Society of Engineering Education: Engineering Design Graphics Division, Williamsburg, Virginia, November 2004.

4. Demel, John et all, "Building a Successful Fundamentals of Engineering for Honors Programs," Proceedings, American Society of Engineering Education: Annual Meeting, Salt Lake City, Utah, June 2004.

5. Baxter, Douglas, H., Bunk, Donald S., "Engineering Graphics and Computer Aided Design,” McGraw Hill, NY, NY, 2001.

6. Halliday, Resnick, Walher, Fundamentals of Physics, $7^{\text {th }}$ Edition, John Wiley \& Sons, NY, 1994.

7. Morris, Alan S., The Essence of Measurement, Prentice Hall, NY, 1996.

8. Mager, Robert F., Preparing Instructional Objectives, Fearon Teachers Aids, NY, 1984.

9. Bunk, Craig, Sneck, "Renewal of Core Engineering at Rensselaer Polytechnic Institute, Final Report," NSF

Planning Grant NSF-02-091 